\title{
Morphometric Analysis of Nasutitermes (Termitidae: Nasutitermitinae) from Sarawak, Malaysian Borneo
}

\author{
Wan Nurainie Wan Ismail ${ }^{*}$, Ratnawati Hazali ${ }^{1}$, Nur Izzah Mat Desa ${ }^{1}$, Norsyarizan Jamil² and Siti Nurlydia Sazali ${ }^{1}$ \\ ${ }^{1}$ Faculty of Resource Science and Technology, Universiti Malaysia Sarawak, \\ 94300 Kota Samarahan, Sarawak, Malaysia. \\ ${ }^{2}$ Public Health Division, The Federal Territory of Labuan Department of Health, State Department of Health, \\ Mailbox 80832, 87018 Wilayah Persekutuan Labuan, Malaysia.
}

\begin{abstract}
This study aims to analyse the soldier's morphological variation of Nasutitermes. In this study, a total of 107 individuals representing six species were appropriately measured and recorded, in which 12 morphometric measurements were used. The morphological comparison was made among six Nasutitermes species used in this study based on the head capsule and shape of rostrum, pronotum and postmentum. Following the comparison between six Nasutitermes species, we suggest that N. regularis and $N$. longinasus were closely resembled to each other than to the remaining four species; $N$. havilandi, N. matangensis, N. matangensiformis and N. fuscipennis based on the external morphological characteristics. The cluster analysis shows by the dendrogram resulted in two major clades; clade 1 grouped almost individuals of $N$. longinasus while clade 2 consists of the remaining five species. Accordingly, this study may serve as a baseline reference for the morphological characteristics that can be used in resolving taxonomic issues for Nasutitermes species.
\end{abstract}

Keywords: nasute termites; morphological variation; Sarawak

\section{INTRODUCTION}

Soldier caste in termite social system is very important for identification (Miura and Matsumoto 2000) since it is the only caste that highly sclerotised and easily differentiates among the others. Nasutitermes species or well known as nasute termites is the largest genus lies under subfamily Nasutitermitinae (Syaukani and Thompson 2011). Subfamily Nasutitermitinae holds a unique characteristic that distinguishes them from other families which is the frontal projection (nasus or rostrum) on the head (Thapa 1981; Tho 1992). The utilisation of morphometric in phylogenetic studies can be one of the contributions to increase the understanding regarding termite taxonomy generally (Lee et al. 2005).

According to Syaukani and Thompson (2011), this genus usually possesses the conical to cylindrical shape of nasus which differentiate them from other genera. Besides, rostrum is specialised to secrete protection fluid to avoid predation for termites' colonies (Thapa 1981). Tho (1992) acknowledged that members of this genus are the most difficult to be distinguished when it relies on their morphological characters. Thus, people usually confused with the other genus within the subfamily. However, there are only a few studies conducted for the past years on the morphological variations.

The main problem faced in Nasutitermes is the species delimitation, and the taxonomic status among members of Nasutitermes is intensely confusing, which always lead to misidentification. Unfortunately, there are limited studies on morphological variation of subfamily Nasutitermitinae notably under genus Nasutitermes (Syaukani and Thompson 2011). In addition, there are several studies of morphometric analysis for other species of termites such as in the genus Odontotermes (i.e. Manzoor \& Akhtar 2006a; 
Manzoor \& Akhtar 2006b; Manzoor 2010) and Coptotermes (i.e. Norsyarizan \& Wan Nurainie 2016; Norsyarizan et al. 2018) but not Nasutitermes, especially in Sarawak.

The morphometric analysis of soldier caste presented in this paper aims to elucidate the morphometric variation among selected species in the genus Nasutitermes aided with cluster analysis. Thus, the diagnostic character(s) resulted then will be useful to enhance the identification process of Nasutitermes effectively. Moreover, accurate termites' taxonomy and recognition are crucial to identify pest species especially for applying the effective termite management (Kirton 2005). The study will provide baseline information to taxonomic of this species in terms of intercolonial variation in the soldier caste.

\section{MATERIALS AND METHODS}

\section{A. Termites Collection}

Nasute termites were collected from three different location in Southwest of Sarawak namely Borneo Highland, Kubah National Park and Kampung Temurang, Padawan. Borneo Highland is located on Mount Penrissen, which is isolated from the central highland spine of Borneo. The area is rich in montane vegetation, and the temperature ranged from $18^{\circ} \mathrm{C}$ to $28^{\circ} \mathrm{C}$ annually. Kubah National Park, on the other hand, is situated on a small sandstone plateau, which mostly covered by mixed dipterocarp forest. This national park has a wide variety of palm tree species and wild orchids in Borneo (Hazebroek \& Abang Kashim 2000). Another termites' locality used in this study is Kampung Temurang, Padawan. Kampung Temurang is about 25 kilometres south of Kuching and one of the tourist spots, famous for the Rafflesia that can be found here. Other than that, Kampung Temurang is surrounded by agricultural activities.

All specimens were collected from the field using a random sampling and standardised protocol by Jones et al. (2005) with a modification of sampling transects following Norsyarizan et al. (2018) (i.e. An area of $100 \mathrm{~m}$ long and $2 \mathrm{~m}$ wide was divided into five small plots with dimension of $20 \mathrm{~m} \times 2 \mathrm{~m}$ one person sampled each and plot for 30 minutes. The samples were preserved in absolute ethanol and brought to the laboratory for identification. All specimens were stored in the Insect Reference Collection, Universiti Malaysia Sarawak (UNIMAS). The identification of termites to the species level was made using taxonomic keys and previous studies published by Ahmad (1965), Thapa (1981) and Tho (1992).

\section{B. Morphological Characterisation and Termites Identification}

The morphological characters were photographed using a Motic SMZ-16B series stereomicroscope attached to a Moticam 2000 camera. General morphological terminology used for describing soldiers follows those of Tho (1992) and Gathorne-Hardy (2001). The calibrated measurements were taken using Motic Image Plus 2.0 software. A total of 107 individuals of soldiers from six Nasutitermes species namely, $N$. longinasus, $N$. fuscipennis, $N$. havilandi, $N$. matangensis, $N$. matangensiformis and $N$. regularis (Table 1) were microscopically examined and identified.

Table 1. Checklist of species used in this study with their localities and number of individuals obtained.

\begin{tabular}{|l|c|c|c|c|}
\hline \multirow{2}{*}{ Species } & \multicolumn{3}{|c|}{ Number of soldiers collected } & \multirow{2}{*}{$\begin{array}{c}\text { Total } \\
\text { individuals } \\
\text { of soldier }\end{array}$} \\
\cline { 2 - 4 } & $\begin{array}{c}\text { Borneo } \\
\text { Highlands }\end{array}$ & $\begin{array}{c}\text { Kubah } \\
\text { National } \\
\text { Park }\end{array}$ & $\begin{array}{c}\text { Kampung } \\
\text { Temurang, } \\
\text { Padawan }\end{array}$ & 29 \\
\hline $\begin{array}{l}\text { Nasutitermes } \\
\begin{array}{l}\text { fuscipennis } \\
\text { Haviland }\end{array}\end{array}$ & 10 & 19 & - & 25 \\
\hline $\begin{array}{l}\text { Nasutitermes } \\
\text { havilandi Desneux }\end{array}$ & - & 25 & - & 32 \\
\hline $\begin{array}{l}\text { Nasutitermes } \\
\text { longinasus } \\
\text { Holmgren }\end{array}$ & 10 & 12 & 10 & 10 \\
\hline $\begin{array}{l}\text { Nasutitermes } \\
\text { matangensis } \\
\text { Haviland }\end{array}$ & - & 10 & - & 6 \\
\hline $\begin{array}{l}\text { Nasutitermes } \\
\text { matangensiformis }\end{array}$ & - & 6 & - & 5 \\
\hline $\begin{array}{l}\text { Holmgren } \\
\text { Nasutitermes } \\
\text { regularis Haviland }\end{array}$ & Total individuals of soldier used \\
\hline
\end{tabular}

Note: '-'not recorded in the respective locality.

Measurements of the soldier body parts follow those in Thapa (1981) and Tho (1992). The following 12 morphometric characters were measured (in millimetres); (1) Head width at point of constriction (HWC); (2) Maximum head width (HW); (3) Length of rostrum (LR); (4) Head length measured to base of mandible (HLM); (5) Head height (HH); (6) Head length with rostrum (LHR); (7) Head length without rostrum (LHxR); (8) Head width to base of mandibles (WHM); (9) Width of postmentum (WPt); (10) Length of postmentum (LPt); (11) Width of pronotum (WPr); and (12) Length of pronotum (LPr). 


\section{Statistical Analysis}

The measured data were analysed by calculating the minimum value, maximum value, average, standard deviation, coefficient of variance and analysis of variance (ANOVA). Tukey-Kramer and cluster analysis were constructed by using squared Euclidean distance. The data obtained were presented using the unweighted pair group method average (UPGMA) cluster analysis using Minitab version 15.1.3, while ANOVA was conducted using SPSS Version 24.0.

\section{RESULTS}

\section{A. Diagnostic Feature Examination}

A morphological comparison was made among the Nasutitermes species used in this study based on the diagnostic features such as head capsule and shape of rostrum (Figure 1), pronotum (Figure 2) and postmentum (Figure 3).

Head capsule: Based on Figure 1, N. longinasus have square-shaped of the head with a flat dorsal profile and possess the largest size. Unlike $N$. havilandi and N. matangensis, which have a round shape, it is rather difficult to distinguish these two species based on the head capsule. On the other hand, $N$. fuscipennis and N. matangensiformis were remarked to own pear-shaped and tear-dropped shape of head capsule (Figure 1D \& $1 \mathrm{~F}$ ). However, N. matangensiformis was usually smaller in size to $N$. fuscipennis with a darker colour at the rostrum part. In this study, it can be observed that $N$. regularis is distinct from other species in term of their head capsule shape, which it exhibits a rectangle shape with light brown colour and dorsal profile is slightly concave (Figure $1 \mathrm{E})$

The shape of rostrum: $N$. longinasus and $N$. regularis significantly have a long elongated cylindrical shape of rostrum but there was slight disparate between both species (Figure $1 \mathrm{~A} \& 1 \mathrm{E}$ ). $N$. regularis have a weakly sharp tip with thicker rostrum at the base compare to $N$. longinasus which has a slightly flat tip with cylindrical shape from the middle to the top. It was observed that the shape of the rostrum of $N$. longinasus is distinctly different from other species. Both $N$. havilandi and $N$. matangensis have cone shape nasus with a sharp tip and thicken at the base. Other than that, $N$. matangensiformis and $N$. fuscipennis also share the same rostrum configuration which has cone shape with ogive shape of the tip. Similar to $N$. havilandi, $N$. matangensiformis have longer rostrum compared to $N$. fuscipennis.
A

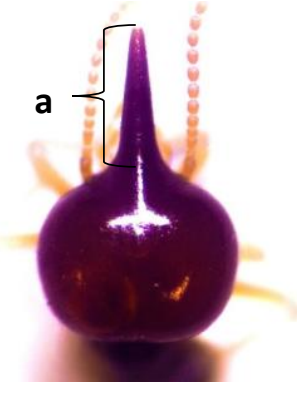

D

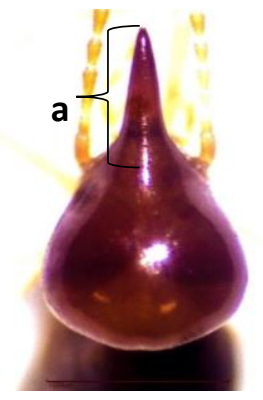

B
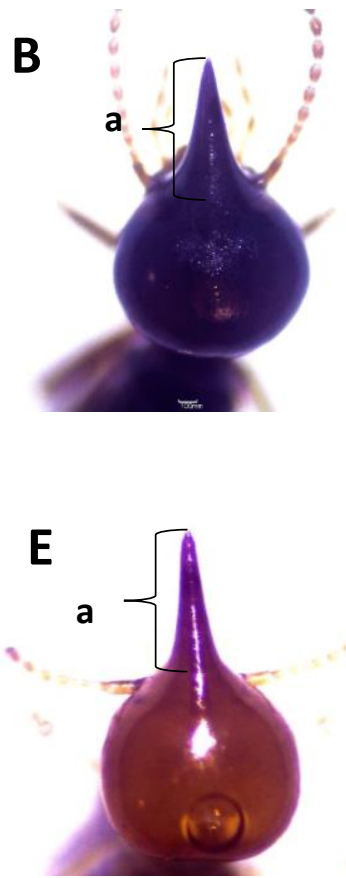
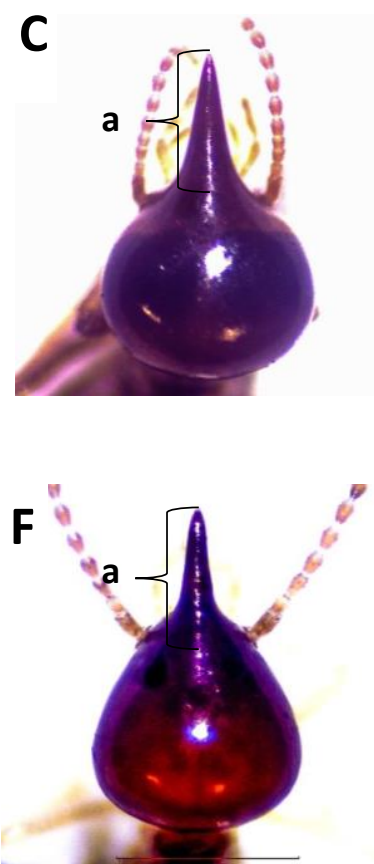

Figure 1. Dorsal view of soldier head and the shape of rostrum (a) of Nasutitermes species under various magnification. A. N. longinasus (30x); B. N. matangensis (40x); C. $N$. havilandi (40x); D. N. fuscipennis (40x); E. N. regularis (40x); F. N. matangensiformis (50x). 
Pronotum: Based on Figure 2, all four species have saddle- analysed in this study. N. matangensis exhibit hemisphereshaped pronotum, namely $N$. longinasus, $N$. havilandi, $N$. shaped of pronotum, which anterior nearly flattened and fuscipennis and N. regularis with slight differences on their more rounded posterior, differ to N. matangensiformis, anterior and posterior alignment. $N$. havilandi exhibit anterior which exhibit oval-shaped with posterior and anterior part margin shallowly emarginated and posterior narrowly rounded, is weakly concave.

which were the most distinct compared to other species
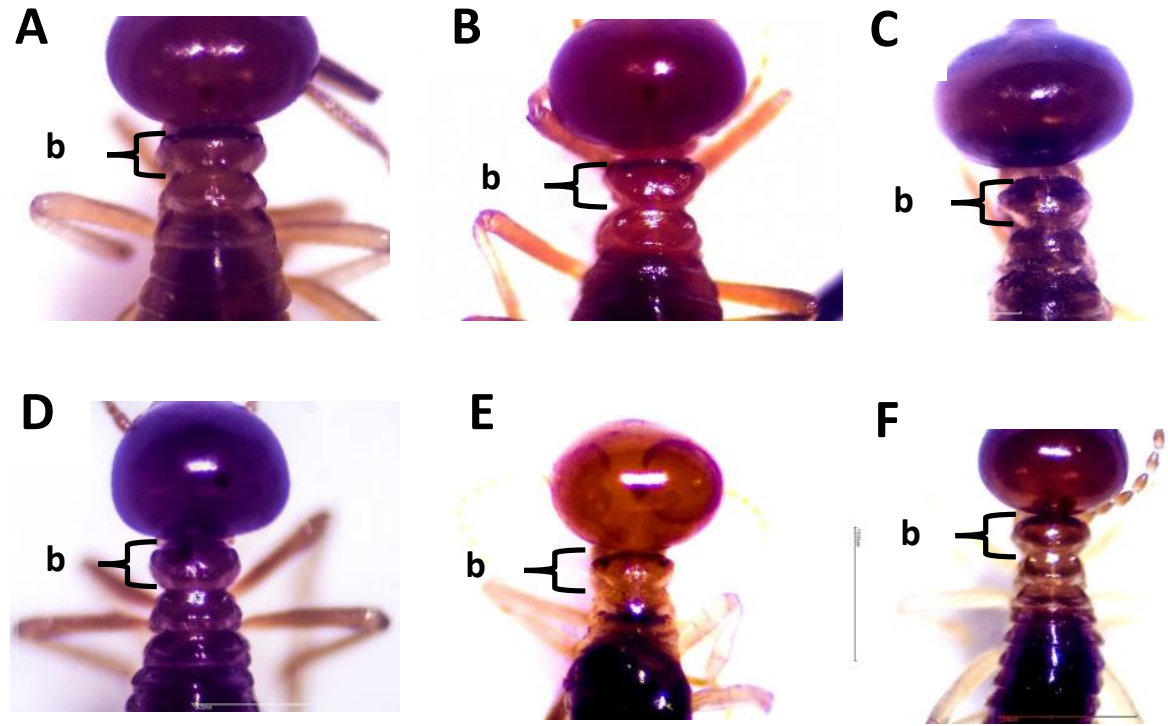

Figure 2. Dorsal view of pronotum (b) of Nasutitermes species under 50x magnification.

A. N. longinasus; B. N. matangensis; C. N. havilandi; D. N. fuscipennis; E. N. regularis; $\mathbf{F}$ N. matangensiformis.

Postmentum: As shown in Figure 3, all species used in this Nasutitermes since it is overlapping among species. study shared a similar shape of postmentum but the width is Nevertheless, $N$. longinasus used in this study appeared to varied (Table 1). Therefore, postmentum was not a suitable be the largest while N. matangensiformis was the smallest characteristic to determine the species level of genus among the four species.
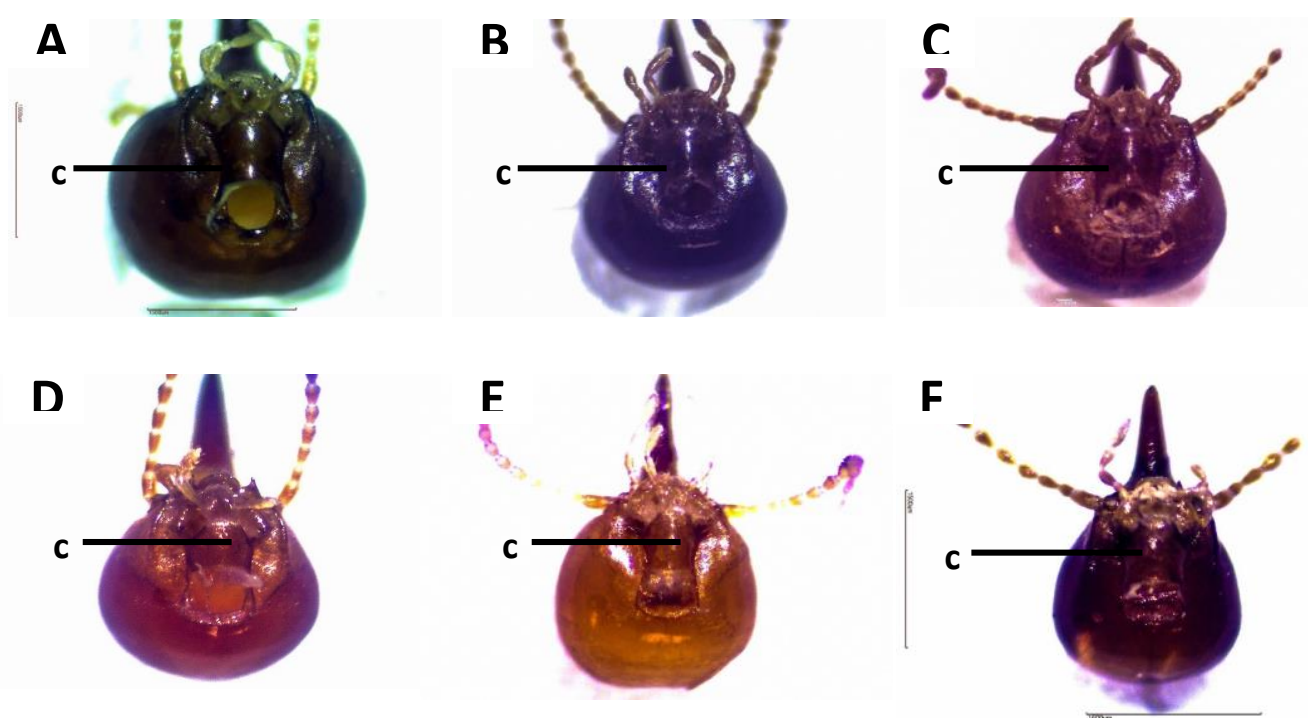

Figure 3. Ventral view of postmentum (c) of Nasutitermes species under 50x magnification. A. N. longinasus; B. N. matangensis; C. N. havilandi; D. N. fuscipennis; E. N. regularis; F. $N$. matangensiformis. 


\section{B. Morphometric variation}

An overview of variation of all characteristics measured in the study was established (Table 2) with ANOVA F-statistics indicating the presence of a significant difference between at least two populations. For 12 morphometric characteristics measured, statistical differences between populations were indicated. Tukey-Kramer testing of individual characteristics provided groupings that indicate significant pairwise population differences (Table 2).

\section{Cluster Analysis}

Cluster analysis using the unweighted pair group method average (UPGMA) resulted in a dendrogram tree as shown in Figure 4. Based on this study, a total of five species (except $N$. longinasus) were clustered under clade 2 , with $31.86 \%$ distance value from clade 1 . In addition, almost all individuals of $N$. longinasus soldiers clustered together and lies under clade 1a. This shows that there are only slight differences between all six species examined and they might share some of the morphological characteristics.

\section{DISCUSSION}

\section{A. Morphological Variation}

$N$. longinasus is the largest species among Nasutitermes species, followed by $N$. havilandi, N. fuscipennis, $N$. matangensis, $N$. matangensiformis and $N$. regularis. However, $N$. longinasus is distinguishable from other species by having square-shaped of the head with the larger size. Even though $N$. longinasus was significantly different from the other Nasutitermes species, it shared a small degree of similarity with $N$. regularis as revealed from this study. Comparably, $N$. regularis exhibit rectangle shape of the head and dorsal profile slightly concave. Following the comparison between six Nasutitermes species used in this study, it is suggested that $N$. regularis and $N$. longinasus were closely resembled to each other than to the remaining four species; N. havilandi, $N$. matangensis, $N$. matangensiformis and $N$. fuscipennis based on external morphological characteristics.

Furthermore, while other species were compared to each other, it was difficult to distinguish between $N$. havilandi and
$N$. matangensis, also between $N$. matangensiformis and $N$. fuscipennis in terms of head capsule, yet distinguishable with the shape of the rostrum. As clearly shown in Figure 1, both species shared the same configuration in terms of the shape of rostrum, which $N$. regularis and $N$. longinasus have long elongated cylindrical rostrum but there was slight disparate towards the end of nasute. Thapa (1981) stated that both $N$. regularis and $N$. longinasus possess elongated shape of the rostrum. Undoubtedly, other characters including head capsule and pronotum are relevant to be used as keys to delineate Nasutitermes termites until the species level, as proven from this study.

According to Thapa (1981) and Ahmad (1965), N. matangensiformis and $N$. fuscipennis are similar to each other, where $N$. fuscipennis distinct from $N$. matangensiformis by having pear-shaped head cone shape of rostrum with ogive shape of tips and larger size. This is consistent with the morphometric finding from this study (Figure 1). However, N. matangensiformis is remarkable by having a tear-dropped shape of the head as shown in Figure 1, which cannot be easily differentiate using naked eyes or under microscope magnification and almost oval-shaped with posterior and anterior part weakly concave pronotum shape. As stated by Thapa (1981), head without rostrum is astonishing sub-circular and nearly linear at dorsal profile. This species can be easily differentiated from the other Nasutitermes species based on size, yet it is still hard to delineate with $N$. fuscipennis if only depending on morphological characters. Nevertheless, the only characteristic besides pronotum that differs between both species $N$. fuscipennis and $N$. matangensiformis are head configuration, which pear-shaped and tear-dropped shape respectively.

The head capsule of $N$. matangensis without rostrum is perfectly rounded as in N. havilandi (Thapa 1981; Syaukani and Thompson 2011). From this study, both species were observed to be slightly different to each other, depending on several morphological characters but almost similar among all six species. In terms of the shape of rostrum, both species have the same configuration of rostrum which is coneshaped nasus with a sharp tip and thickened at the base. The only difference is the length of the nasus, in which $N$. havilandi have longer nasus than $N$. matangensis. 
Therefore, the shape of the rostrum is unreliable for species identification. Other than that, both species can be distinguished using pronotum shape as shown in Figure 2, in which $N$. havilandi possessed hairy saddle-shaped pronotum with anterior margin shallowly emarginated and posterior narrowly rounded, while in $N$. matangensis the pronotum is almost hemisphere-shaped, which anterior margin nearly flattened while posterior is rounded. Therefore, this diagnostic feature (Figure 2) is a reliable character to distinguish between $N$. havilandi and N. matangensis.

\section{B. Morphometric Analysis of Nasutitermes Based on UPGMA}

Presented distance value unravel that $N$. longinasus is significantly different from the other five Nasutitermes species, supported with $p<0.05$. Other remarkable characteristics of $N$. longinasus which distinguished it from other species, includes a flattened dorsal profile of the head, an elongated cylindrical shape of rostrum with a slightly flat tip and a larger size of saddle shape pronotum.

In addition, the cluster of $N$. havilandi and $N$. fuscipennis under clade 1a showed that the localities of termites might have a direct effect towards morphological characters especially size. The colony of $N$. havilandi that lies under clade 1a was collected from Rayu trail, Kubah National Park, whereas N. fuscipennis were from Borneo Highland. Both sampling site in this study can be considered as highland area, which consists mountainous land at high altitude. Chown and Klok (2003) stated that altitude directly influences the morphological size of insects; the higher latitude which correlated with altitude, the insect may be larger. This is consistent with the result obtained from this study, shown in Figure 4. Nevertheless, two individuals originated from different colony found clustered on the same clade $1 \mathrm{~b}$, which both soldiers from $N$. havilandi may have a wider range of morphological size that influence their clade position as shown in the result.

From this study, the cluster analysis showed that $N$. havilandi and $N$. fuscipennis located at both clade 1a and clade 2 indicated that both species almost of the same size. Furthermore, the grouping of species by cluster analysis used as shown in the dendrogram is still reliable for species identification, although it does not fully resolve in the present study. Therefore, extensive sampling needs to be done with a greater number of individuals and colonies to be included in further analysis in order to clarify the relationship between each clade. In addition, the morphological character of a species might differ or similar due to ecological conditions or habitat distribution and historical factors, such as continental drift, orogeny, and climatic variations (Boulogne et al. 2017).

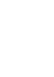


Table 2. Descriptive statistics of studied Nasutitermes species.

\begin{tabular}{|c|c|c|c|c|c|c|c|c|c|c|c|c|c|c|c|c|c|c|}
\hline \multirow{2}{*}{$\begin{array}{l}\text { Species } \\
\text { Character }\end{array}$} & \multicolumn{3}{|c|}{$N$. havilandi $(\mathrm{n}=\mathbf{2 5})$} & \multicolumn{3}{|c|}{ N. fuscipennis $(\mathrm{n}=\mathbf{2 9})$} & \multicolumn{3}{|c|}{$N$. longinasus $(\mathrm{n}=32)$} & \multicolumn{3}{|c|}{ N. matangensis $(\mathrm{n}=10)$} & \multicolumn{3}{|c|}{ N. matangensiformis $(\mathrm{n}=6)$} & \multicolumn{3}{|c|}{ N. regularis $(\mathrm{n}=5)$} \\
\hline & $\operatorname{Mean} \pm \mathbf{S D}$ & Min & Max & $\operatorname{Mean} \pm \mathbf{S D}$ & Min & $\underset{\mathbf{x}}{\mathbf{M a}}$ & $\operatorname{Mean} \pm$ SD & Min & Max & $\operatorname{Mean} \pm \mathbf{S D}$ & Min & Max & $\operatorname{Mean} \pm$ SD & Min & Max & $\operatorname{Mean} \pm$ SD & Min & Max \\
\hline HWC & $0.52 \pm 0.15^{a, b}$ & 0.26 & 0.72 & $0.41 \pm 0.18^{\mathbf{b}, \mathbf{c}}$ & 0.25 & 0.62 & $0.62 \pm 0.06^{a}$ & 0.49 & 0.75 & $0.44 \pm 0.16^{\mathbf{b}}$ & 0.29 & 0.73 & $0.20 \pm 0.01^{d}$ & 0.19 & 0.21 & $0.29 \pm 0.01^{\mathrm{c}, \mathrm{d}}$ & 0.27 & 0.30 \\
\hline HW & $1.09 \pm 0.09^{\mathbf{b , c}}$ & 0.87 & 1.23 & $1.12 \pm 0.09^{b}$ & 1.03 & 1.26 & $1.46 \pm 0.12^{\mathrm{a}}$ & 1.21 & 1.65 & $1.10 \pm 0.03^{\mathbf{b , c}}$ & 1.08 & 1.19 & $0.74 \pm 0.03^{d}$ & 0.72 & 0.79 & $0.99 \pm 0.04^{\mathrm{c}}$ & 0.93 & 1.02 \\
\hline LR & $0.72 \pm 0.15^{b}$ & 0.40 & 0.91 & $0.70 \pm 0.12^{b}$ & 0.54 & 0.13 & $1.17 \pm 0.05^{\mathrm{a}}$ & 1.06 & 1.27 & $0.74 \pm 0.06^{\mathbf{b}}$ & 0.65 & 0.86 & $0.51 \pm 0.01^{\mathrm{c}}$ & 0.50 & 0.52 & $0.67 \pm 0.04^{b}$ & 0.63 & 0.71 \\
\hline HLM & $1.16 \pm 0.06^{\mathbf{b}}$ & 0.95 & 1.23 & $1.19 \pm 0.16^{\mathbf{b}}$ & 0.80 & 1.47 & $1.37 \pm 0.12^{\mathrm{a}}$ & 1.24 & 1.90 & $1.09 \pm 0.04^{\mathbf{b , c}}$ & 1.03 & 1.16 & $0.96 \pm 0.02^{\mathrm{c}}$ & 0.92 & 0.99 & $1.17 \pm 0.04^{b}$ & 1.06 & 1.16 \\
\hline $\mathrm{HH}$ & $0.78 \pm 0.05^{\mathbf{b}, \mathbf{c}}$ & 0.68 & 0.88 & $0.83 \pm 0.06^{\mathbf{b}}$ & 0.63 & 0.94 & $0.99 \pm 0.18^{a}$ & 0.81 & 1.44 & $0.80 \pm 0.05^{\mathbf{b}, \mathbf{c}}$ & 0.71 & 1.08 & $0.54 \pm 0.03^{\mathrm{d}}$ & 0.49 & 0.59 & $0.71 \pm 0.01^{b}$ & 0.70 & 0.72 \\
\hline WHM & $0.51 \pm 0.10^{\mathrm{a}}$ & 0.40 & 0.85 & $0.43 \pm 0.07^{\mathbf{a}, \mathbf{b}}$ & 0.25 & 0.55 & $0.48 \pm 0.04^{a}$ & 0.41 & 0.55 & $0.44 \pm 0.05^{\mathbf{a}, \mathbf{b}}$ & 0.39 & 0.53 & $0.29 \pm 0.01^{\mathrm{c}}$ & 0.28 & 0.31 & $0.39 \pm 0.02^{b}$ & 0.37 & 0.43 \\
\hline LHR & $1.70 \pm 0.08^{b}$ & 1.51 & 1.84 & $1.72 \pm 0.18^{b}$ & 1.39 & 2.05 & $2.40 \pm 0.10^{\mathrm{a}}$ & 2.15 & 2.55 & $1.73 \pm 0.06^{b}$ & 1.62 & 1.80 & $1.37 \pm 0.05^{\mathrm{c}}$ & 1.30 & 1.42 & $1.71 \pm 0.03^{b}$ & 1.66 & 1.76 \\
\hline LHxR & $0.79 \pm 0.09^{b}$ & 0.68 & 1.04 & $0.88 \pm 0.10^{\mathbf{b}}$ & 0.62 & 1.61 & $1.09 \pm 0.16^{a}$ & 0.81 & 1.67 & $0.82 \pm 0.10^{b}$ & 0.73 & 1.06 & $0.62 \pm 0.02^{\mathrm{c}}$ & 0.59 & 0.63 & $1.04 \pm 0.04^{b}$ & 0.99 & 1.06 \\
\hline WPt & $0.32 \pm 0.03^{b}$ & 0.25 & 0.36 & $0.31 \pm 0.04^{b}$ & 0.25 & 0.39 & $0.39 \pm 0.04^{a}$ & 0.32 & 0.58 & $0.29 \pm 0.02^{\mathbf{b}, \mathbf{c}}$ & 0.26 & 0.32 & $0.26 \pm 0.02^{\mathrm{c}}$ & 0.22 & 0.27 & $0.30 \pm 0.05^{\mathbf{b}, \mathbf{c}}$ & 0.26 & 0.38 \\
\hline $\mathrm{LPt}$ & $0.33^{2} .0 .03^{b}$ & 0.28 & 0.39 & $0.31 \pm 0.04^{b}$ & 0.23 & 0.37 & $0.43 \pm 0.04^{a}$ & 0.33 & 0.55 & $0.30 \pm 0.04^{b}$ & 0.23 & 0.34 & $0.25 \pm 0.01^{\mathrm{c}}$ & 0.24 & 0.26 & $0.32 \pm 0.03^{b}$ & 0.29 & 0.36 \\
\hline WPr & $0.53 \pm 0.03^{\mathbf{b}, \mathbf{c}}$ & 0.49 & 0.58 & $0.58 \pm 0.08^{\mathbf{a}, \mathbf{b}}$ & 0.49 & 0.73 & $0.61 \pm 0.04^{\mathrm{a}}$ & 0.46 & 0.61 & $0.51 \pm 0.04^{\mathrm{c}, \mathrm{d}}$ & 0.44 & 0.55 & $0.43 \pm 0.01^{\mathrm{e}}$ & 0.42 & 0.43 & $0.45 \pm 0.02^{\mathrm{d}, \mathrm{e}}$ & 0.43 & 0.48 \\
\hline LPr & $0.24 \pm 0.03^{\mathrm{a}}$ & 0.20 & 0.31 & $0.26 \pm 0.03^{\mathrm{a}}$ & 0.21 & 0.33 & $0.24 \pm 0.03^{a}$ & 0.17 & 0.30 & $0.25 \pm 0.02^{\mathrm{a}}$ & 0.22 & 0.27 & $0.23 \pm 0.09^{\mathrm{a}}$ & 0.17 & 0.41 & $0.19 \pm 0.02^{b}$ & 0.16 & 0.20 \\
\hline Rostrum-Head Index & $1.23 \pm 0.38^{b, c}$ & 0.76 & 1.94 & $1.28 \pm 0.25^{\mathbf{a}, \mathbf{b}}$ & 0.75 & 1.88 & $0.92 \pm 0.21^{\mathrm{c}}$ & 0.07 & 1.47 & $1.12 \pm 0.15^{\mathbf{b}, \mathbf{c}}$ & 0.87 & 1.41 & $1.21 \pm 0.02^{\mathbf{b}, \mathbf{c}}$ & 1.17 & 1.24 & $1.56 \pm 0.10^{\mathrm{a}}$ & 1.42 & 1.67 \\
\hline Postmentum Index & $0.99 \pm 0.10^{\mathrm{a}}$ & 0.76 & 1.17 & $1.01 \pm 0.13^{\mathrm{a}}$ & 0.86 & 1.45 & $0.94 \pm 0.08^{a}$ & 0.81 & 1.15 & $0.99 \pm 0.16^{\mathrm{a}}$ & 0.79 & 1.29 & $1.02 \pm 0.10^{\mathrm{a}}$ & 0.84 & 1.09 & $0.92 \pm 0.07^{\mathrm{a}}$ & 0.87 & 1.04 \\
\hline
\end{tabular}

Note: Mean, within rows, followed by the different letter are significantly different ( $\mathrm{p}<0.05$; Tukey's HSD).

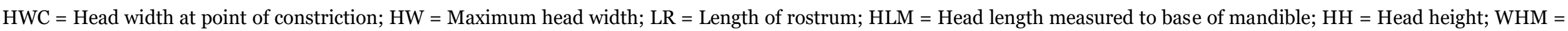

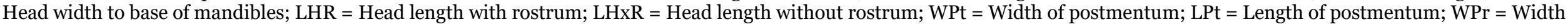
of pronotum; LPr = Length of pronotum. 


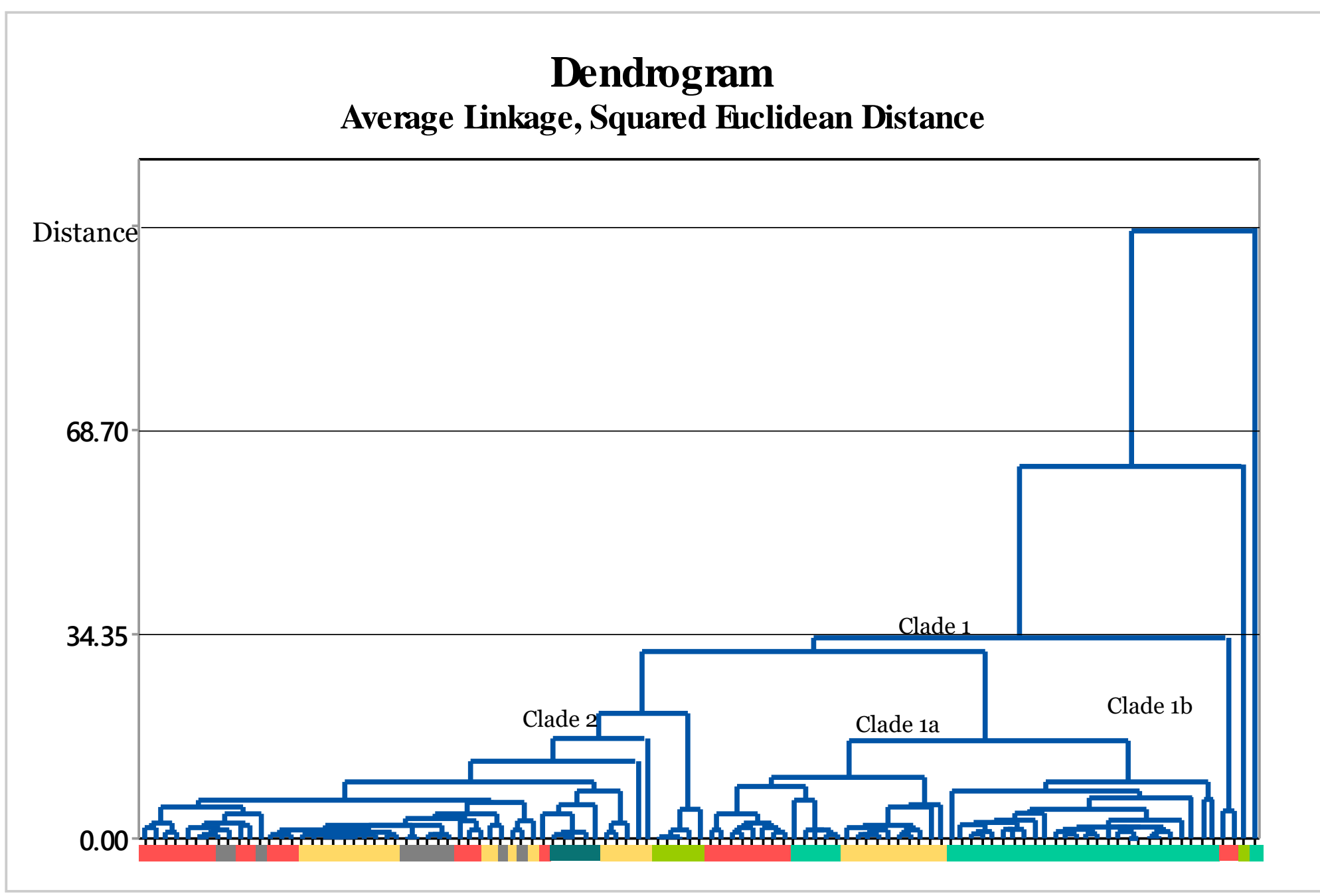

Legend:

N. havilandi

N. fuscipennis

N. longinasus

N. matangensis

N. matangensiformis

N. regularis

Figure 4. Dendrogram of the morphological relationship of Nasutitermes species analysed using 12 morphometric measurements and UPGMA algorithm on standardised variables based on average linkage and squared Euclidean distances. 


\section{CONCLUSION}

In summary, species delineation using morphological characters are rather complicated among Nasutitermes species understudied, taking into account most of them fall under the same cluster, which suggested that they may have similar configuration based on phenotypic appearance. This suggested they might be high in homogeneity. However, they still exhibited some heterogeneity that contributes to morphology adaptability and makes them slightly different from other species within the Nasutitermes genus. Hence, a phylogenetic study using molecular should be further used for reviewing and to compare the molecular genetics finding with this morphometric result in order to provide comprehensive revision on this particular Nasutitermes.

\section{ACKNOWLEDGEMENT}

Malaysia Ministry of Higher Education funded this project under Research Acculturation Grant Scheme (RAGS/1180/2014-03). The authors wish to thank Forest Department Sarawak for Research Permit No. NPW.907.4.4 (Jld.14)-63 and Park Permit No. WL32/2017 and Sarawak Forestry Corporation for access to facilities and study sites. The authors would also like to thank the Faculty of Resource Science and Technology, UNIMAS for the administrative supports.

\section{REFERENCES}

Ahmad, M 1965, 'Termite (Isoptera) of Thailand', The Bulletin of the American Museum of Natural History, vol. 131, no. 1, pp. 1-114.

Arif, A, Taskirawati, I, \& Affandi 2010, 'Morphometric analysis of Coptotermes sp. population from two different nests', Jurnal Perennial, vol. 6, no. 2, pp. 60-69.

Boulogne, I, Constantino, R, Amusant, N, Falkowski, M, Rodrigues, AMS, \& Houël, E 2017, 'Ecology of termites from the genus Nasutitermes (Termitidae: Nasutitermitinae) and potential for science-based development of sustainable pest management programs', Journal of Pest Science, vol. 90, no.1, pp. 19-37.

Hazebroek, HP \& Abang Kashim, AM 2000, National Parks of Sarawak. Natural History Publication (Borneo), Kota Kinabalu.

Kirton, LG 2005, 'The importance of accurate termite taxonomy in the broader perspective of termite management', eds CH Lee \& WH Robinson, in Proceedings of the Fifth International Conference on Urban Pests, P\&Y Design Network, Penang, Malaysia, pp. 1-7.

Lee, CY, Forschler, BT \& Jenkins, TM 2005, 'Taxonomic questions on Malaysia termites (Isoptera: Termitidae) answered with morphology and DNA biotechnology', eds $\mathrm{CH}$ Lee \& WH Robinson, in Proceedings of the Fifth International Conference on Urban Pests, International Conference on Urban Pests (ICUP), pp. 205-211.
Manzoor, F 2010, 'Morphometric analysis of population samples of soldier caste of Odontotermes takensis (Ahmad) (Isoptera: Termitidae: Macrotermitinae', Pakistan Journal of Zoology, vol 42, no. 1, pp 37-40.

Manzoor, F, \& Akhtar, MS 2006a, 'Morphometric analysis of population samples of soldier caste of Odontotermes obesus (Rambur) (Isoptera, Termitidae, Macrotermitinae)', Animal Biodiversity and Conservation, vol 29, no. 2, pp 91-107.

Manzoor, F, \& Akhtar, MS 2006b, 'A detailed morphometric study of population samples of Odontotermes walloensis (Wasman) (Isoptera: Termitidae: Macrotermitinae) from India', Zoo's Print Journal, vol. 21, no. 11, pp. 2479-2482.

Miura, T, \& Matsumoto, T 2000, 'Soldier morphogenesis in a nasute termite: discovery of a disc-like structure forming a soldier nasus', Proceedings of the Royal Society of London B vol 267, pp. 1185-1189.

Norsyarizan, J, \& Wan-Nurainie WI 2016, 'Morphological variation of selected species of Coptotermes (Isoptera: Rhinotermitidae) in Western Sarawak', Serangga, vol. 21, no. 1, pp. 1-38.

Norsyarizan, J, Wan-Nurainie, WI, \& Veera- Singham, G. 2018, 'Morphometric variation and genetic relationship of Coptotermes spp. (Blattodea: Rhinotermitidae) in Sarawak, Malaysia,' Malaysian Applied Biology, vol. 47, no. 6, pp 113-125.

Syaukani, S, \& Thompson, GJ 2011, 'Taxonomic notes on 
Nasutitermes and Bulbitermes (Termitidae,

Nasutitermitinae) from the Sunda region of Southeast Asia based on morphological and molecular characters', ZooKeys, vol. 148, pp. 135-16o.

Thapa, RS 1981, 'Termites of Sabah', Sabah Forest Records, vol 12, pp 1-374.

Tho, YP 1992, 'Termites of Peninsular Malaysia' eds Kirton LG, in Malayan Forest Records No. 36. Forest Research Institute of Malaysia, Kepong. 